Article

\title{
Rehabilitation as a Disability Equality Issue: A Conceptual Shift for Disability Studies?
}

\author{
Tom Shakespeare ${ }^{1, *}$, Harriet Cooper ${ }^{1}$, Dikmen Bezmez $^{2}$ and Fiona Poland ${ }^{1}$ \\ ${ }^{1}$ Norwich Medical School, University of East Anglia, Norwich, NR4 7TJ, UK; E-Mails: tom.shakespeare@uea.ac.uk (T.S.), \\ h.cooper@uea.ac.uk (H.C.), f.poland@uea.ac.uk (F.P.) \\ ${ }^{2}$ College of Social Sciences and Humanities, Koç University, 34450 Istanbul, Turkey; E-Mail: dbezmez@ku.edu.tr
}

* Corresponding author

Submitted: 29 September 2017 | Accepted: 14 February 2018 | Published: 26 March 2018

\begin{abstract}
Rehabilitation is a controversial subject in disability studies, often discussed in terms of oppression, normalisation, and unwanted intrusion. While there may be good reasons for positioning rehabilitation in this way, this has also meant that, as a lived experience, it is under-researched and neglected in disabilities literature, as we show by surveying leading disability studies journals. With some notable exceptions, rehabilitation research has remained the preserve of the rehabilitation sciences, and such studies have rarely included the voices of disabled people themselves, as we also demonstrate by surveying a cross-section of rehabilitation science literature. Next, drawing on new research, we argue for reframing access to rehabilitation as a disability equality issue. Through in-depth discussion of two case studies, we demonstrate that rehabilitation can be a tool for inclusion and for supporting an equal life. Indeed, we contend that rehabilitation merits disability researchers' sustained engagement, precisely to ensure that a 'right-based rehabilitation' policy and practice can be developed, which is not oppressive, but reflects the views and experiences of the disabled people who rehabilitation should serve.
\end{abstract}

\section{Keywords}

concept; disability; equality; rehabilitation; rights

\section{Issue}

This article is part of the issue "Disability Equality: In Theory and Practice", edited by Mark Priestley (University of Leeds, UK) and Lisa Waddington (Maastricht University, The Netherlands).

(C) 2018 by the authors; licensee Cogitatio (Lisbon, Portugal). This article is licensed under a Creative Commons Attribution 4.0 International License (CC BY).

\section{Introduction}

Definitions of rehabilitation are contested. For example, outside clinical care, the term has been used in social contexts, which include vocational rehabilitation helping people access employment, and in rehabilitating exoffenders. The focus of this article is health-related rehabilitation. The World Health Organisation (WHO) defines rehabilitation based on the International Classification of Functioning, Disability and Health:

As set of measures that assist individuals who experience, or are likely to experience, disability to achieve and maintain optimal functioning in interaction with their environments. (WHO, 2011, p. 96)

In this approach, disability is defined as a decrement in functioning, which rehabilitation can help reduce. In the WHO approach, as expressed in the World Report on Disability (2011), rehabilitation comprises rehabilitation medicine; physical, occupational and other therapies; and assistive devices. However, in the Convention on the Rights of Persons with Disabilities (CRPD; UN, 2006), rehabilitation is conceptualised as a broader process of social transformation which may not have been explicitly realised in rehabilitative practices to date. 
Tensions in both definitions of, and attitudes to, rehabilitation run through this article. Two of the authors have an insider status (Corbin Dwyer \& Buckle, 2009), one having experienced childhood habilitation for hemiplegia, the other having experienced in-patient rehabilitation after spinal cord injury as an adult. The former experienced physiotherapy as a profoundly intrusive experience, impinging much more on her life than the direct effects of her relatively mild impairment. It was partly through reflecting on her experience of habilitation that she came to disability studies, finding it to be an emancipatory academic (and activist) space. Conversely, the latter experienced physiotherapy as empowering, enabling him to regain functioning and thus maximise his social participation. These divergent attitudes to rehabilitation reflect a wider ambivalence within the disability rights community.

Authors within the materialist disability studies tradition have re-defined disability in terms of social barriers and oppression, rather than deficits in personal functioning (Oliver, 1990), otherwise known as the 'social model'. The goal of this disability rights approach is to remove environmental barriers and discrimination, whereas rehabilitation may be considered suspect because it attempts to fix the origins of limitations within individuals (Finkelstein, 1980). Disability studies academics have written of their personal experience of rehabilitation as oppressive, because they see it as emphasising "normalisation" (Abberley, 1995; Finkelstein, 2004; Oliver, 1990, 1993). For example, in his professorial inaugural lecture, Michael Oliver (1993) posed the question 'what's so wonderful about walking?', and thereby querying the very desirability of 'optimal functioning'. Later, Michael Oliver and Colin Barnes asserted that:

Clearly the concept of rehabilitation is laden with normative assumptions clustered around an ablebodied/mind ideal. And, despite its limitations in terms of returning people with acquired impairments such as spinal cord injury, for example, to their former status, it has little or no relevance or meaning for people born with congenital conditions such as blindness or deafness other than to enforce their sense of inadequacy and difference. (Oliver \& Barnes, 2012, p. 42)

That some disabled people hold ambivalent views about rehabilitation may be understandable, especially when seeing the development of rehabilitation within a historical context where the statistical norm became an increasingly influential referent for medical practice (Davis, 1995; Gibson, 2016). Furthermore, within this branch of disability studies, rehabilitation is understood as a practice that is 'done to' rather than 'done with' the collaboration of the patient. Within this context, rehabilitation professionals may understandably be experienced as suspect, because representing a mode of acting towards disabled people that privileges the professional's voice over that of the patient (Finkelstein, 1980).
While there may be good reasons for positioning rehabilitation in this way, this has also meant that, as a lived experience, it is under-researched and neglected (Shakespeare, 2014). With some notable exceptions (e.g., Bevan, 2014; Bezmez, 2016; Crisp, 2000; Hammell, 2006; Swart \& Horton, 2015), rehabilitation research has therefore, by default remained the preserve of the rehabilitation sciences. This is reflected in our analysis of recent papers (January 2011 to December 2015) published in the four leading disability studies journals (Disability and Society, Alter, Scandinavian Journal of Disability Research, Disability Studies Quarterly). Of 954 articles published, only 41 ( $4 \%)$, focused on rehabilitation. This might indicate relatively low research interest, especially given the relevance of rehabilitation in many disabled people's lives. Some research does prioritise the lived experience of disability in rehabilitation, with research studies focusing on participatory, inclusive and patient-centred rehabilitation (e.g., Byrnes et al., 2012; Lund, Tamm, \& Bränholm, 2001) and in health settings (Cook \& Inglis, 2012). Additionally, there is other research based on first-person perspectives of individuals going through rehabilitation (e.g., Arntzen, Hamran, \& Borg, 2015; Chun \& Lee, 2013).

Nonetheless the critique remains that, firstly, most of this work comes from rehabilitation sciences scholarship which remains separated from disability studies and, secondly, that both fields of study would benefit from mutual contributions. For instance, Chun and Lee (2013) identify feelings of gratitude when comparing levels of injury with individuals whose impairments are more severe, following traumatic spinal cord injury. Disability scholars might be critical of this comparison. On the other hand, if disability scholars engaged with rehabilitation sciences this might facilitate more nuanced approaches to rehabilitation.

From the rehabilitation sciences perspective, the scope of the materialist disability research critique of rehabilitation, as highlighted in Oliver's previous quotation, could itself be criticised. For example, spinal cord injury rehabilitation measures for muscles, bowels, bladder, skin are all about living healthily in the new, paralysed, status, not regaining the former status of being "a walker" (WHO, 2014). Second, there is a danger in traducing the whole field of rehabilitation when challenging the cure obsession of some charity campaigns. Finally, contradicting Oliver and Barnes (2012), people who are born with or who acquire sight or hearing loss, do experience habilitation and rehabilitation interventions and assistive technologies, such as magnifiers, white canes, cochlear implants and other corrective surgery. Some papers by 'founding fathers' in materialist disability studies are more nuanced, such as Finkelstein (1984), who concludes that, where patients are actively involved, medicine and rehabilitation can and should prevent and mitigate impairment.

To balance the emphasis on disability studies, three multi-disciplinary rehabilitation journals were also se- 
lected for review: The International Journal of Therapy and Rehabilitation; Disability and Rehabilitation and; Clinical Rehabilitation for the same search dates, but this time studies were included where the voices of patients were heard in rehabilitation processes, particularly focusing on two conditions: one congenital (cerebral palsy) and one acquired (spinal cord injury). The 164 rehabilitation science articles reviewed produced no substantial evidence of public and patient involvement-in contrast to the more developed practices of participatory and emancipatory research in the disability studies literature (Oliver \& Hasler, 1987). Fewer than $10 \%$ of articles indicated that research participants were involved in some way, such as data analysis, interview piloting or checking transcripts (Bourke, Hay-Smith, Snell, \& Dejong, 2015; Byrnes et al., 2012; Chun \& Lee, 2013; Dew, Llewellyn, \& Balandin, 2014; Guilcher et al., 2013; Huang, Wang, \& Chan, 2013; Kim \& Shin, 2012; Moll \& Cott, 2013; Papadimitriou \& Stone, 2011; Shikako-Thomas, Bogossian, Lach, Shevell, \& Majnemer, 2013; Smith, Papathomas, Martin Ginis, \& Latimer-Cheung, 2013; Goodridge et al., 2015; Van de Velde et al., 2012).

Moll and Cott (2013) present insights yielded by qualitative research with adults with cerebral palsy, who reported on the problems of a 'rehabilitation' wholly conceived as 'normalisation'. Such an approach to interventions did not offer people with cerebral palsy what they needed to be able to manage their bodies as they age (Moll \& Cott, 2013). However, this article appears unique within the cerebral palsy literature in questioning received ideas about rehabilitation. Other important insights in this literature include: an emphasis on agency rather than autonomy, which might help rehabilitation patients to adjust to their new situation and to be more comfortable with themselves (Van de Velde et al., 2012; see also Bezmez, 2016; Papadimitriou, 2008). The experience of psychological loss associated with acquired impairment should not be underestimated (Clifton, 2014). For congenital and lifelong impairments, an emphasis on nourishing bodily self-awareness and on learning how to manage the ageing body may be more appropriate than an emphasis on normalisation (Brunton \& Bartlett, 2013; Moll \& Cott, 2013). Despite these positive insights, our reviews of literature suggest that rehabilitation is marginal within disability studies, and the voices of disabled people are marginal within rehabilitation sciences. The lack of emphasis on the voices of disabled people might in part reflect the professional focus of the rehabilitation science journals searched, and their preference for methodologies with measurable outcomes over qualitative methodologies which privilege the opinions and experiences of participants.

Health-related rehabilitation comprises a very broad and diverse set of interventions, and rehabilitation professionals vary in their outlook and behaviour. Not all rehabilitation interventions are experienced as appropriate, let alone effective; some professionals act in oppressive ways (Oliver, 1993). The disability community itself has a range of views and experiences regarding rehabilitation. Many disabled people derive considerable benefit from habilitation and rehabilitation: some regain the ability to walk (as with $10 \%$ of people with spinal cord injury including one of the current authors); others regain functional speech; many manage to use artificial limbs successfully. The danger surely lies in a blanket dismissal of a whole area of healthcare and human experience. A more nuanced approach is required.

Shakespeare (2014) has argued that the materialist disability studies commitment to a 'strong' social model has hampered the development of disciplinary alliances (for example, with medical sociology) that could lead to research promoting the human rights of all disabled people. He and others reject the dualist social model understanding of disability as over-simplified and reductionist. Rather than reducing disability to either impairment, or barriers or oppression, they call for a relational approach to disability, which conceptualises disability as the outcome of the interactions between the person with the impairment, and the wider context. Critical realists set out a "laminated" approach (Danermark \& Gellerstedt, 2004), referring to different levels of reality. From this perspective, the range of appropriate responses to disability could include: healthcare to prevent or treat the health condition; rehabilitation to maximise functioning; psychological interventions; removal of barriers in environments; social provision of independent living supports; legal protections to combat discrimination.

The ambiguous position of rehabilitation within progressive responses to disability is also evidenced in human rights law. Within the CRPD, rehabilitation is covered under Article 25, Health, and Article 26, Rehabilitation. Article 25 explicitly states 'States parties shall take all appropriate measures to ensure access for persons with disabilities to health services that are gendersensitive, including health-related rehabilitation'. This suggests that there is a right to health-related rehabilitation, within an overall right to health. Article 26 calls on all States to:

Take effective and appropriate measures...to enable persons with disabilities to attain and maintain maximum independence, full physical, mental, social and vocational ability, and full inclusion and participation in all aspects of life. To that end, States Parties shall organize, strengthen and extend comprehensive habilitation and rehabilitation services and programmes.

Yet, significantly, Article 26 does not conceptualise any distinct right to rehabilitation. This appears to be because Convention was negotiated under a somewhat contradictory UN General Assembly mandate to draft a treaty that paralleled existing human rights instruments, rather than one which created new rights (Kayess \& French, 2008, p. 20). Because there had been no explicit right to rehabilitation in the existing human rights architecture, it was not expressed as a stand-alone right 
in the CRPD. Equality in the CRPD is often phrased in terms of disabled people achieving access to, for example, services, "on an equal basis to others". Yet when it comes to a specific service such as rehabilitation, which may be particularly relevant to people with long-term conditions, it is not then a matter of equality with nondisabled people. It is a matter of meeting needs associated with impairments. Without appropriate rehabilitation, people cannot enjoy equality of opportunity in education and employment. Drawing on new research taking place at the University of East Anglia, we argue in this article that rehabilitation and access to rehabilitation is therefore a disability equality issue. We call for a dialogue between disability studies/disability rights and rehabilitation sciences (see also Bevan, 2014; Hammell, 2006; Gibson, 2015).

Through an in-depth discussion of two case studies, which examine in detail the meaning of rehabilitation as a social experience in the lives of disabled people, we demonstrate that rehabilitation can be a tool for inclusion and for an equal life. Indeed, we contend that rehabilitation merits a sustained engagement from disability researchers precisely to help ensure a 'right-based rehabilitation' policy and practice can be developed which is not oppressive, but which instead reflects the views and experiences of the disabled people it should serve.

\section{Methods}

Our qualitative research explores the importance and meaning of health-related rehabilitation seen as a social process in disabled people's lives. This article draws on primarily two research studies. The first explored disabled people's experiences of, and views about, rehabilitation in England: this study included people with differing congenital and acquired impairments and was based on semi-structured interviews, focus groups and a creative writing group (Case study 1 ). The second study looked at disabled people who had experienced acquired brain injury or who had undergone amputations, on two wards of a rehabilitation hospital in England, and entailed in-depth interviews, focus group discussions and participant observations (Case study 2). Although the main findings of this research are drawn from these two research studies, at times the article draws on comparable findings from an ethnographic research project conducted previously in Turkey by one of the authors. For the purposes of this article, the various forms of data have been used to generate rich case studies, which reflect the wider data, but specific experiences with analytic resonance and relevance are presented for discussion here (Crowe et al., 2011).

The first case study is drawn from Harriet Cooper's ongoing research project, 'Rights-based Rehabilitation: A qualitative research project co-produced with disabled people'. This project is being supported by an advisory group of disabled individuals which meets to discuss aspects of research design, implementation, analysis and dissemination. While the data has now largely been collected, a comprehensive phenomenological analysis of themes in the data is yet to be completed. The emergent themes to be discussed here are indicative rather than comprehensive or definitively situated within the broader data set. This particular case study was therefore selected for inclusion in this article as it offers a wide-ranging critical illustration of ways in which rehabilitation can be understood as a disability equality issue. The richness of the case study was facilitated by the rapport developed between Mary (not her real name) and Harriet during the course of the interview, and through their shared interest in disability rights.

The second case study is drawn from fieldwork undertaken from October 2016 to February 2017, including interviews with 10 patients and 8 family members and focus group discussions with doctors (4), nurses (5), physiotherapists and occupational therapists (6). Additionally, participant observation was undertaken with 5 families as they were visiting the patients; finally, 5 in-depth interviews were conducted with academic experts in rehabilitation. All the interviewees staying in the neurological services were patients with mental capacity, who could consent and talk. Our first contact with interested participants was initiated by a member of the staff and we were then invited to meet with the patients and their families. The particular case study was selected because it introduces an important social aspect of physical rehabilitation, in providing room for socialisation and peer support. This theme was not examined in the first case study. The study has several limitations: first, the original focus of the second research study lies in examining the role of the family in in-patient rehabilitation in the UK. Thus, interview questions primarily focused on family roles with information on rights-based rehabilitation to promote disability equality being derived from the responses to these questions, to set the framework for the case study. In consequence, some data on rehabilitation services and dynamics specific to rehabilitation such as rehabilitation techniques were not available. However, the emphasis on the importance of having a communal rehabilitation experience remained essential. Second and relatedly, the focus on family roles made it necessary to draw on the fieldwork conducted in the amputee service to ensure the depth and soundness of the analysis in Case study 2.

The studies received ethical permission from the UEA Faculty of Medicine and Health Sciences Research Ethics Committee and the South East Coast Brighton \& Sussex NHS Research Ethics Committee, respectively. All the names in the case studies have been changed.

\section{Results and Discussion}

The two case studies analysed in this section emphasise different aspects of rights-based rehabilitation. Thus, even though they have themes that overlap, they are in fact more complementary in terms of initiating a discus- 
sion on rights-based rehabilitation, which can promote disability equality. The first case foregrounds the issues of maintaining access to services, i.e. the question of whether rehabilitation is withheld or restricted, and the appropriateness of the treatments on offer. This raises the central question of whether rehabilitation offered is relevant to the patient's needs. The second case discusses an issue often neglected in health-related rehabilitation, namely the importance of making room for socialisation and peer support while receiving healthrelated treatment. This case provides information which broadens existing conceptions of rehabilitation. The firstperson accounts in both case studies demonstrate how all three issues have significance for developing rightsbased rehabilitation to promote disability equality.

\subsection{Case Study 1: Mary}

\subsubsection{Mary's 'Battle' for Access}

Mary is a woman in late middle age, who has been living with multiple sclerosis for thirty-five years. In her interview, she described her different struggles as she sought to access rehabilitation services. Mary deployed a battle metaphor (including the 'big battle' and the 'constant battle') when she identified where rehabilitation was withheld, or restricted, and when she believed it was not relevant to her needs:

Later on, to me rehabilitation wasn't actually responding to me, it was, um, it had put me in a category, a person with MS, er...who therefore would have...set treatments....Um, and everything turned into a battle because, it wasn't actually what I was wanting...or what I needed.

The concept of the battle was used frequently by Mary to characterise her experience; as a result it appears several times in the case study, even when the data is being discussed in terms of another theme. It is a relevant detail because it highlights the amount of energy that was expended by Mary to obtain and maintain access to the rehabilitation services she needed.

\subsubsection{Obtaining Appropriate Treatment: The Importance of User Involvement}

Mary described her struggle to obtain the immunesuppressing treatment beta-interferon, and her experience of being categorised as someone who would not benefit from it. She appealed to the Health Secretary, and eventually won the right to receive the treatment, which she found had a profoundly positive effect on her relapsing-remitting $\mathrm{MS}$.

Mary also described her efforts to receive the right treatment for continence control as 'a struggle' and as something which 'again turned into a battle':
People wanted to catheterise me. Again, er, because it was easier and cheaper than getting people in to help me get to the toilet. So that again was a struggle because I found a catheter very uncomfortable; my bladder reacts to it and pushes it out.

For Mary, being helped to use the toilet via a toileting sling allowed her to maintain muscle strength and lung capacity; she regarded it as part of her rehabilitation. Moreover, using a catheter had caused her to suffer severe bladder infections. Yet the care providers restricted the number of continence pads she could have and the frequency of the care-workers' visits to assist her with toileting, which again began a battle of proving need for pads and care-worker visits. These experiences are perceived to have 'turned into' battles, due to 'shrinking availability' of services. When something 'turns into' a battle, there is the implication that energy and resources could have been saved-on all sides-if the 'battle' simply were not necessary.

\subsubsection{Resource-Scarcity Creates Access and Equality Issues}

Several times, Mary made a connection between a failure to have her needs met and the rationing of state resources. She talked about how she lost her access to assistance with her arm splints, when the relevant healthcare professional moved away and was not replaced, meaning that Mary's arm splints have gradually deteriorated. In Mary's experience, decisions have been made on the basis of cost-effectiveness rather than being taken in accordance with need.

At one stage there had been an attempt to remove her continuous physiotherapy and to offer Mary only a limited number of sessions, after which she would have had to return to her GP and request a new referral. According to Mary, this was not because her own need had decreased, but because others were not able to access the physiotherapy they needed. Again, Mary had to appeal to the health authority, and won her case.

\subsubsection{Rights-Based Rehabilitation Makes Space for the Voices of Disabled People}

As well as depicting her struggle against rationing of scarce NHS resources, Mary's story also illustrates the specific relevance of the concept of 'expert by experience'. Mary found that she needed to contest received ideas about what would be right for her. Her knowledge and understanding were sometimes overlooked, and the views of medical professionals dominated. Sometimes this seemed to be because the NHS had a fixed notion of the needs of a person with MS, rather than a flexible notion relevant to her own experience of disability. Sometimes it seemed to be because of discriminatory assumptions about disabled people. For example, she reported that it was suggested to her that one way to avoid the 
need for a more expensive wheelchair would be to go to bed during the day, but she felt this would dramatically reduce her quality of life:

I have a different view on what I want to do, and I want to, I want to live, until I die, and that's the way I want to do it, and so again it's a battle of how I want to do it.

Mary's commitment to self-determination, and to 'follow[ing] her instinct' have contributed to her success in obtaining access to rehabilitation services. A less empowered or supported individual might have conformed and lost control and functioning.

\subsubsection{Uncertainty about Access Can Erode One's Sense of Personhood}

One of the long-term effects of the uncertainty Mary has experienced in relation to service provision has been to erode her sense of entitlement, and even her sense of personhood. Mary explained that she felt as though she was a 'burden':

It's like...you've had-you've had your character deconstructed....You lose your right to be the person you were because you're taking resources, and therefore you will do as you're told.

When her physiotherapy was withdrawn, Mary's condition went downhill, and she also experienced considerable distress at the uncertainty of not knowing whether her treatment would continue, affecting her ability to plan or to maintain her health:

The distress...when you don't know that people are going to agree with you...is quite profound, and stress, is the thing that triggers $\mathrm{MS}$, which makes it worse, so it was actually damaging me.

Mary located the problem in the 'systems' and not in the individuals who were involved in her rehabilitation, whom she held in high regard. With one significant exception, the rehabilitation professionals Mary had encountered were, in her words, 'wonderful'.

In summary, huge amounts of emotional, physical and administrative labour were involved in the process of fighting for what Mary needs to maintain her quality of life. She has had some very positive experiences of rehabilitation but reports that she has had to struggle to obtain the right services for herself on an ongoing basis. Mary joked that while her husband could enjoy retirement, she still had the full time job of arranging her access to care and treatment.

\subsection{Case Study 2: Robert}

The main themes discussed in Mary's case related to maintaining access to rehabilitation and the appropriate- ness of treatments on offer. This second case study highlights a different theme, in order to argue that rehabilitation is also a disability equality issue because it can affect opportunities for disabled people to be part of relevant social networks and to take part in social interactions, when going through the rehabilitation process itself. Limited opportunities for socialisation during rehabilitation can lead to feelings of loneliness and despair at a time which can already bring many challenges. We argue that although traditionally and practically it has not always been the case, in-patient rehabilitation is distinctive when compared to other treatment experiences, because it is supposed to facilitate a transition to a new life with a new bodily status. Often this process takes months or even years, which precludes a quick cure for the patient. Rehabilitation is a process for managing liminality (Hammell, 2006), which necessitates the creation of spaces that contain some of the characteristics of the everyday life beyond the hospital walls. Socialisation is one of those characteristic processes. Another is the way that families personalise routines and environments to make them familiar and welcoming to their loved ones. We argue that rehabilitation can promote disability equality if it develops a holistic approach to the complex needs of individuals who experience it. The discussion below illustrates this claim in the light of the experiences in two different hospital wards, neurological and amputee services, in a specialist rehabilitation hospital in England. We identify how the way that rehabilitation is organised may lead to a sense of isolation and loneliness in people. Similar to the case of Mary, we show that this state of affairs is not perceived as a failure of the individual professionals by the patient, for staff are described as doing everything they can. Again, this case demonstrates that when an individual's complex needs are not met, this can erode that individual's sense of personhood, and stir up feelings of being a "burden". At a more general level, both case studies draw attention to the importance of including disabled people within rehabilitation processes through practices which can integrate their complex needs. Both case studies also highlight how people are disabled by society as well as by their bodies. Mary's case demonstrated this in critically discussing fixed ideas about disability which are based on NHS assumptions rather than on patients' needs; the second case study illustrates this by drawing attention to the lack of attention paid to the patients' need to socialise as they go through rehabilitation.

Robert (not his real name) is a 72-year-old man, who in the previous eight months had had one hip replacement operation, two strokes, and two brain operations, eventually leading to him living with the condition of epilepsy. At the time of the interview, he had been an in-patient in the neurological rehabilitation service for about a month. Robert was estranged from most of his family members and the only person who occasionally visited him was his partner, with whom he had been having an on-and-off relationship over recent years. He was staying in a single room, which he associated with feel- 
ings of "being stuck in", because he had not been out of his room on his own since he had been in the hospital. Asked about what he disliked about rehabilitation, he responded: "The things I don't like is being stuck to that bed; being stuck in this room".

Throughout the interview, Robert emphasised themes related to feelings of isolation, loneliness, despair and despondence. Asked about his plans for the time after discharge Robert replied:

I don't know if things are going to get any worse. My eyesight has diminished ever so much since the stroke. I get very despondent. Loneliness I've never felt, I've been lonely before many times in my life but I've never felt lonely, do you understand?.... Now I feel it as loneliness, it's despair sometimes. I don't think there is anything else I can tell you. Nobody told me anything about what a stroke entails when I had it....What to expect and that is frightening when you get these things thrown at you umm.....I've lost an awful lot because of the stroke. I've no confidence now, whereas before I was self-confident in everything I did. That's what worries me about getting discharged and going back to the flat. How will I cope?

Robert's feeling of living now with loneliness not only relates to his complicated past, as someone who is estranged from the family, or the dramatic change he had to go through in his life situation, but also to how the rehabilitation process itself is organised. His emphasis on how he had never felt being lonely as "loneliness", before having had the stroke, and "being stuck" in the room, is telling in that respect. Similarly, the experiences of some patients in the amputee service, as explained in subsequent paragraphs, demonstrate that if complementary services such as peer support and provision of space for socialisation were to be integrated into existing rehabilitation schemes, patients' experience of rehabilitation might change significantly. This sense of isolation demonstrates the complex needs of individuals as they go through in-patient rehabilitation, and the importance of being part of relevant social networks as a feature of rights-based rehabilitation that promotes disability equality. In this context Robert seemed to value highly any interaction with staff. Asked about what he liked about rehabilitation, he answered:

The things I do like are the nurses; they do everything they can for you...they are really nice.

Thus, as seen in the case for Mary, Robert also did not perceive the sources of his distress as deriving from the individual staff members. At the same time, it was hard for Robert to call for the nurses every time he needed them:

They say all the nurses here are good they get you what you need in the night. You don't realise how much you do need when you can't walk because I get out of bed and walk over to that container with the wipe sheets or the light switch I've got to get someone to come and do it...which I don't like. I think it's wasting their time.

Similarly to Mary's reported experiences of uncertainty about her sense of personhood, when encountering problems in accessing services, Robert's experiences of such feelings of loneliness and despair led him to question his own enacted personality and the relationships he did or did not form over the years:

In my previous life I wasn't very nice person to anybody...I was a nasty person. I'd hurt people.

Robert's experience of in-patient rehabilitation is telling, in illustrating how, in an already-challenging life episode entailing increased fragility and need for support, experiences of being additionally secluded by the conditions of rehabilitation, engendering feelings of being "stuck" to a bed in a room with few social interactions, can add unhelpful feelings of loneliness and despair. We contend that a rights-based rehabilitation practice promoting disability equality needs to engage with the psychological impact of acquiring impairment as well, and foreground the importance here of forming meaningful social networks.

Within the framework of the same field study, interviews and participant observation were also conducted in the amputee rehabilitation service of the same hospital. The amputee rehabilitation service differed from the neurological service, in that most patients were not individually isolated, but stayed in rooms for three or four people. Furthermore, most patients in the amputee ward did not experience the cognitive difficulties specific to the experience of many patients within the neurological services, such as loss of memory or confusion. As a result, the amputee service emerges as offering a space that may be more conducive than some other rehabilitation services to generating feelings of community and camaraderie.

This specificity in organising and experiencing the amputee service was highlighted in our various casual chats with the staff members, even from setting up arrangements for interviews. At the initial stage of reaching out to interested participants, NHS staff acted as mediators. The first time we were informed about interested patients, a staff member flagged up three people, all of whom wanted to be interviewed. These were all patients staying in the same room, who had been informed about the study at the same time and collectively decided to participate. In addition, when we first went into the ward to make appointments with the respective patients, they were sitting in their wheelchairs in a semi-circle, and socialising. Our initial meeting to arrange the interview dates was also a collective gathering, where patients were having a social welcoming chat with us. Our sub- 
sequent meetings in the amputee ward involved similar, more socially-interactive encounters, which felt quite different from our recruitment experience in the neurological service settings. Sometimes, patients spontaneously referred to other patients' experiences with whom they shared their room. For instance, Kate was explaining some problems she was having in her interactions with the staff and suggested that Lisa had similar issues:

In fact that upset me and that upset Lisa. I may be speaking out of turn, but she probably won't even tell you because she is very, very quiet.

Thus, for Kate this was a collectively-experienced problem, described almost as a "patients versus the staff" polarising discourse, which could be perceived as illustrating the collective character of rehabilitation for amputee patients and the shared sense of community and camaraderie in the amputee ward.

The interviews conducted with the patients in the amputee service did not bring up themes of loneliness. This was not because patients were not stressed about making a transition to a life with an amputated leg. This transition is experienced as stressful; and needs to be planned, especially when it comes to issues of accessibility at home after discharge. Yet, the loneliness and despair mentioned by Robert and several other participants in the neurological services were not mentioned by the participants in the amputee ward. To a certain extent, this might have to do with the particularities of the different impairments. Yet, we contend that a rehabilitation process which enabled patients to share collectively the rehabilitation process in time and space, also plays a significant factor. This is corroborated by findings from a previous study conducted in a Turkish rehabilitation hospital, demonstrating how opportunities for socialisation as patients went through the rehabilitation process, constituted one of the most important aspects of the whole experience:

The thing we liked most were our meetings in the evening after dinner time...We would get together about 10-12 people....We would not talk about our illness but have general chat (about the government, the economy)....Everyone would be telling their stories about parts of their lives. (Mehmet-not real name)

These more specific insights link contexts with experiences of rehabilitation, showing that rehabilitation can promote disability equality if it makes space for forming social networks within the process, rather than engendering isolation or other life-disruptions or patients, where they are not essential or intrinsic to the treatment process, as, for instance, experiences of pain and nausea within life chemotherapy. We realise the complexities of accomplishing this goal, especially since it requires service providers to develop a patient-focused, comprehen- sive, holistic understanding of rehabilitation. Yet, if rehabilitation practices are indeed about facilitating a transition into a new life with a new bodily status, this complexity needs to be acknowledged. As such, disability equality can be promoted by facilitating access to rehabilitation services that are based on an adequate assessment of patients' complex needs. The importance of comprehensive rehabilitation programmes has been highlighted by both the aforementioned Article 26 of the CRPD, and a considerable amount of literature (e.g., Byrnes et al., 2012; Dewar \& Nolan, 2013; Falkenberg, 2007). Some literature also discussed the specific significance of socialisation and peer support in reducing psychological stress and promoting wellbeing during in-patient and community-based rehabilitation (Jain, McLean, Adler, \& Rosen, 2016; Parker et al. 2016; Szalai et al., 2017). One additional factor to highlight here relates to the potential value of developing appropriate inner architectural design to allow more room for socialisation. In this respect, our earlier experience in the Turkish rehabilitation hospital demonstrated the importance of having communal spaces, like inner courtyards, while undergoing rehabilitation. Although sociological studies have often neglected the role of the built environment in medical practice (Martin, Nettleton, Buse, Prior, \& Twigg, 2015), we argue for its significance in rehabilitation, and particularly in a rights-based approach.

\section{Limitations of This Research}

The authors are working towards a conception of rightsbased rehabilitation, which undoubtedly requires more evidence, analysis and debate, also drawing on the contributions of others (Siegert \& Ward, 2010; Skempes \& Bickenbach, 2015). Key features of this approach are that it should:

- Be based on partnership with disabled people, for example through peer support;

- Make space for the voices of disabled people;

- Refer to a comprehensive, holistic understanding of rehabilitation where the complex needs of patients are taken into consideration;

- Be open to diverse ways of functioning, rather than imposing rigid normalisation of impaired bodies;

- See assistive technology as a valid alternative strategy for functioning, rather than a tool for normalisation;

- Understand that people are disabled by society as well as by their bodies, requiring a wider response that challenges social and economic disempowerment;

- Understand that health-related rehabilitation is relevant and important to many but not all people with impairment.

More consultation with wider communities of disabled people is needed before these elements can be validated. 
We note that others have stressed freedom, well-being, and dignity as key features of a human rights perspective on rehabilitation, and we would not contest this. However, we would argue for the importance of taking a political as well as a philosophical perspective.

Our literature review was limited by our choice of journals for review and selected time-frame. For example, Disability and Rehabilitation published articles on disability rights in the year before our review started (Siegert \& Ward, 2010); moreover, there are other journals in the health-related rehabilitation field, some of which are more ready to publish rights-based papers (Skempes \& Bickenbach, 2015). The lack of emphasis on the voices of disabled people might in part reflect the professional focus of the rehabilitation science journals searched, and their preference for methodologies with measurable outcomes over qualitative methodologies which privilege the opinions and experiences of participants. A future literature search might include occupational therapy journals, for example, to examine whether voices remain as marginal in this field. It should also be noted that the a small but burgeoning field of critical rehabilitation studies, exemplified by groups such as the Critical Physiotherapy Network (https://criticalphysio.net) is also beginning to challenge prevailing discourses.

Our empirical research was qualitative, and based in one English county, and a few rehabilitation settings, and a few disability organisations, with less than 50 respondents in total. Our interpretations are inevitably interpretative and can be accused of being subjective, like all qualitative research. Using this data, it is impossible to draw broad conclusions about the wider rehabilitation sector, or the total population of individuals experiencing rehabilitation. The original focus of the second research study lies in finding out the role of the family in in-patient rehabilitation in the UK. Thus, interview questions primarily focused on family role and information on rights-based rehabilitation to promote disability equality was derived from the responses to these questions, which set the framework of the case study. As such, some data on rehabilitation services and dynamics specific to rehabilitation like for instance techniques of rehabilitation were not available. Still the emphasis on the importance of having a communal rehabilitation experience is essential. Second and related to the first point, the focus on family role made it necessary to draw upon the fieldwork conducted in the amputee service. Data collected in the amputee service enriched the depth and soundness of the analysis in case study.

\section{Concluding Remarks}

The premise of this article is that disability is both a decrement in functioning, and the experience of barriers and discrimination. The disability rights and rehabilitation sciences approaches offer different and equally valid ways of dealing with the loss that often comes with impairment, one which celebrates the resilience of individuals and their capacity to adapt, and the other which calls for society to adapt. We contend that rehabilitation merits sustained engagement from disability researchers as well as rehabilitation scientists, in order to develop rights-based rehabilitation schemes that promote disability equality. For this purpose, based on the first-person accounts and experiences of primarily two disabled people, who go through health-related rehabilitation, Mary and Robert, this article sought to find out the main contours of rights-based rehabilitation. Mary and Robert's experiences foregrounded three important components of rights-based rehabilitation.

First, if rehabilitation is one of the diverse needs faced by many disabled people, then access to rehabilitation is an equality issue. Mary's interview reveals that accessing rehabilitation can be a real 'battle'. Resilience, determination and expertise about one's needs can sometimes be a prerequisite to obtaining access to the right services, and these strengths are not available to all disabled people. Mary struggled to obtain rehabilitation services such as ongoing physiotherapy to keep her muscles in use, and she had to fight for this when she was being encouraged to opt for treatments such as muscle relaxants, which, in her lived experience, reduced her physical capacities and were likely to make her more dependent in the long-term.

Second, beyond the issue of accessing services, there appears to be an equality issue around perceptions of what was right for Mary, which seemed at times to be shaped by others' views about the kind of quality of life she can expect as a disabled person, rather than drawing on Mary's own knowledge of how she can best be supported, via rehabilitation, to determine her own life. Therefore, rights-based rehabilitation must genuinely acknowledge the importance of disabled people's own views and choices regarding their lives and expectations, not as a matter of lip service, through dialogue between professional and patient to form the basis of the service.

Finally, the ways that rehabilitation services are delivered have to be sensitive to the other needs that disabled people also have, beyond the physical (Shakespeare, 2014), to be healed emotionally, to connect with others, to participate, to make sense of their lives. In other words, rights-based rehabilitation would be holistic, rather than reductionist. Robert's sense of isolation and loneliness demonstrated the significance of services that provide room for social networks and peer support, and that they need to be understood as essential aspects of rehabilitation. This point is emphasised also by Skempes and Bickenbach (2015), who argue for an extension of rehabilitation services to ensure that people's needs are properly covered. They call for a rights-based approach to rehabilitation, which considers holistic models of care provision that move beyond a curative approach and "promote alternative means of optimizing functioning such as self-management and peer support". Similarly, Siegert and Ward (2010) refer to a study by Slet- 
teb $\varnothing$, Caspari, Lohne, Aasgaard and Nåden (2009), whose qualitative interviews in an in-patient setting for people with traumatic head injuries suggested that support enhanced dignity.

In-patient rehabilitation is not like any other treatment process. It takes often longer and is supposed to aim at facilitating a transition to a new life with a new bodily status. Hence, room should be allowed for some aspects of everyday life that are conventionally associated with life beyond the hospital walls.

The case studies demonstrate that resource constraints in the UK health system appeared to restrict choices, possibly making it harder to achieve rightsbased rehabilitation services. This could erode the individual's sense of personhood/entitlement and reinforce feelings of being a "burden". It is exactly for this reason that closer collaboration between disability and rehabilitation scholars and research on rehabilitation as a lived experience is needed.

The UK has better rehabilitation services than most of the world, and a stronger emphasis on patient autonomy than many cultures. In many developing countries, the full implementation of rehabilitation policies has 'lagged' due to a number of 'systemic barriers' (WHO, 2011, p. 104). Among these barriers, the WHO cites 'absence of engagement with people with disabilities' in relation to the design, delivery and evaluation of rehabilitation services (2011, p. 105). So it is not simply a matter of funding services, but also developing and managing services in ways which are empowering and which help people enjoy their rights as disabled people. There is an urgent need to improve understanding and dialogue between the rehabilitation profession and the disability community (Hammel, 2006), in all parts of the world. Rehabilitation sciences need to take on the human rightsbased approach which now dominates global and national policy on disability (UN, 2006; WHO 2011). Just as importantly, disability studies and disability policy need to make space for the contribution of health-related rehabilitation, as one element in a multi-disciplinary approach to improving the lives of disabled people (Shakespeare, 2014).

\section{Acknowledgements}

Harriet Cooper's project about rights-based rehabilitation received funding from the Collaboration for Leadership in Applied Health Research and Care (CLAHRC) in the East of England. Dikmen Bezmez' project about the role of the family in rehabilitation has received funding from the European Union's Horizon 2020 research and innovation programme under grant agreement No. 701075. We acknowledge the contribution of Swati Kale and Kate Lee in conducting these two research projects.

\section{Conflict of Interests}

The authors declare no conflict of interests.

\section{References}

Abberley, P. (1995). Disabling ideology in health and welfare-The case of occupational therapy. Disability and Society, 10(2), 221-232.

Arntzen, C., Hamran, T., \& Borg, T. (2015). Body, participation and self-transformations during and after inpatient stroke rehabilitation. Scandinavian Journal of Disability Research, 17(4), 300-320.

Bevan, J. (2014). Disabled occupational therapists: Asset, liability...or 'watering down' the profession? Disability and Society, 29(4), 583-596.

Bezmez, D. (2016). Looking for a 'cure': Negotiating 'walking' in a Turkish rehabilitation hospital. Disability and Society, 31(3), 389-405.

Bourke, J. A., Hay-Smith, E. J. C., Snell, D. L., \& Dejong, G. (2015). Attending to biographical disruption: The experience of rehabilitation following tetraplegia due to spinal cord injury. Disability \& Rehabilitation, 37(4), 296-303.

Brunton, L. K., \& Bartlett, D. J. (2013). The bodily experience of cerebral palsy: A journey to self-awareness. Disability \& Rehabilitation, 35(23), 1981-1990.

Byrnes, M., Beilby, J., Ray, P., Mclennan, R., Ker, J., \& Schug, S. (2012). Patient-focused goal planning process and outcome after spinal cord injury rehabilitation: Quantitative and qualitative audit. Clinical Rehabilitation, 26(12), 1141-1149.

Chun, S., \& Lee, Y. (2013). 'I am just thankful': The experience of gratitude following traumatic spinal cord injury. Disability \& Rehabilitation, 35(1), 11-19.

Clifton, S. (2014). Grieving my broken body: An autoethnographic account of spinal cord injury as an experience of grief. Disability \& Rehabilitation, 36(21), 1823-1829.

Cook, T., \& Inglis, P. (2012). Participatory research with men with learning disability: Informed consent. Tizard Learning Disability Review, 17(2), 92-101.

Corbin Dwyer, S., \& Buckle, J. L. (2009). The space between: On being an insider-outsider in qualitative research. International Journal of Qualitative Methods, 8(1), 54-63.

Crisp, R. (2000). A qualitative study of the perceptions of individuals with disabilities concerning health and rehabilitation professionals. Disability and Society, 15(2), 355-367.

Crowe, S., Cresswell, K., Robertson A., Huby, G., Avery, A., \& Sheikh, A. (2011). The case study approach. BMC Medical Research Methodology, 11(1), 100-108.

Danermark, B., \& Gellerstedt, L. C. (2004). Social justice: Redistribution and recognition. A non-reductionist perspective on disability. Disability and Society, 19(4), 339-353.

Davis, L. (1995). Enforcing normalcy: Disability, deafness, and the body. London and New York: Verso.

Dew, A., Llewellyn, G., \& Balandin, S. (2014). Exploring the later life relationship between adults with cerebral palsy and their non-disabled siblings. Disability 
\& Rehabilitation, 36(9), 756-764.

Dewar, B., \& Nolan, M. (2013). Caring about caring: Developing a model to implement compassionate relationship centred care in an older people care setting. International Journal of Nursing Studies, 50, 1247-1258.

Falkenberg, E. (2007). Holistic aural rehabilitation: A challenge. Scandinavian Journal of Disability Research, 9(2), 78-90.

Finkelstein, V. (1980). Attitudes and disabled people. New York: World Rehabilitation Fund.

Finkelstein, V. (1984). Rehabilitation services. In T. Lobstein \& Namibia Support Committee Health Collective (Eds.), Namibia: Reclaiming the peoples' health. AON Publications.

Finkelstein, V. (2004). Representing disability. In J. Swain, S. French, C. Barnes, \& C. Thomas (Eds.), Disabling barriers, enabling environments. London: Sage.

Gibson, B. (2016). Rehabilitation: A post-critical approach. Florida: Taylor and Francis.

Goodridge, D., Rogers, M., Klassen, L., Jeffery, B., Knox, K., Rohatinsky, N., \& Linassi, G. (2015). Access to health and support services: Perspectives of people living with a long-term traumatic spinal cord injury in rural and urban areas. Disability \& Rehabilitation, 37(16), 1401-1410.

Guilcher, S. J. T., Craven, B. C., Mccoll, M. A., LemieuxCharles, L., Casciaro, T., \& Jaglal, S. B. (2012). Application of the Andersen's health care utilization framework to secondary complications of spinal cord injury: A scoping review. Disability \& Rehabilitation, 34(7), 531-541.

Hammell, K. W. (2006). Perspectives on disability \& rehabilitation: Contesting assumptions; Challenging practice. London: Churchill Livingstone.

Huang, I.-C., Wang, Y.-T., \& Chan, F. (2013). Employment outcomes of adults with cerebral palsy in Taiwan. Disability \& Rehabilitation, 35(3), 228-235.

Jain, S., McLean, C., Adler, E., \& Rosen, C. (2016). Peer support and outcome for veterans with posttraumatic stress disorder (PTSD) in a residential rehabilitation program. Community Mental Health Journal, 52(8), 1089-1092.

Kayess, R., \& French, P. (2008). Out of darkness into light? Introducing the Convention on the Rights of Persons with Disabilities. Human Rights Law Review, 8(1), 1-34.

Kim, H.-R., \& Shin, H. I. (2012). When is it appropriate to deliver a prognosis to Korean persons with acute spinal cord injury? Disability \& Rehabilitation, 34(16), 1396-1403.

Lund, M. L., Tamm, M., \& Bränholm, I. (2001) Patients' perceptions of their participation in rehabilitation planning and professionals' view of their strategies to encourage it. Occupational Therapy International, 8(33), 151-167.

Martin, D., Nettleton, S., Buse, C., Prior, L., \& Twigg, J. (2015). Architecture, embodiment and health care: A place for sociology. Sociology of Health \& IIIness, 37, 1007-1022.

Moll, L. R., \& Cott, C. A. (2013). The paradox of normalization through rehabilitation: Growing up and growing older with cerebral palsy. Disability \& Rehabilitation, 35(15), 1276-1283.

Oliver, M. (1990). The politics of disablement. Basingstoke: Macmillan.

Oliver, M. (1993). What's so wonderful about walking? Inaugural Professorial Lecture, University of Greenwich, February. Retrieved from http://disabilitystudies.leeds.ac.uk/files/library/Oliver-PROFLEC.pdf

Oliver, M., \& Barnes, C. (2012). The new politics of disablement. Basingstoke: Palgrave Macmillan.

Oliver, M., \& Hasler, F. (1987). Disability and self-help: A case study of the Spinal Injuries Association. Disability, Handicap and Society, 2(2), 113-125.

Papadimitriou, C. (2008). Becoming en-wheeled: The situated accomplishment of re-embodiment as a wheelchair user after spinal cord injury. Disability \& Society, 23(7), 691-704.

Papadimitriou, C., \& Stone, D. (2011). Addressing existential disruption in traumatic spinal cord injury: A new approach to human temporality in inpatient rehabilitation. Disability \& Rehabilitation, 33(21/22), 2121-2133.

Parker, S., Dark, F., Newman, E., Korman, N., Meurk, C., Siskind, D., \& Harris, M. (2016). Longitudinal comparative evaluation of the equivalence of an integrated peer-support and clinical staffing model for residential mental health rehabilitation: A mixed methods protocol incorporating multiple stakeholder perspectives. BMC Psychiatry, 16, 1-21.

Shakespeare, T. (2014). Disability rights and wrongs revisited. Abingdon: Routledge.

Shikako-Thomas, K., Bogossian, A., Lach, L. M., Shevell, M., \& Majnemer, A. (2013). Parents' perspectives on the quality of life of adolescents with cerebral palsy: Trajectory, choices and hope. Disability \& Rehabilitation, 35(25), 2113-2122.

Siegert, R. J., \& Ward, T. (2010). Dignity, rights and capabilities in clinical rehabilitation. Disability and Rehabilitation, 32, 2138-2146.

Skempes, D., \& Bickenbach, J. (2015). Strengthening rehabilitation for people with disabilities: A human rights approach as the essential next step to accelerating global progress. American Journal of Physical Medicine and Rehabilitation, 94, 823-828.

Sletteb $\varnothing$, A., Caspari, S., Lohne, V., Aasgaard, T., \& Nåden, D. (2009). Dignity in the life of people with head injuries. Journal of Advanced Nursing, 65, 2426-2433.

Smith, B., Papathomas, A., Martin Ginis, K. A., \& LatimerCheung, A. E. (2013). Understanding physical activity in spinal cord injury rehabilitation: Translating and communicating research through stories. Disability \& Rehabilitation, 35(24), 2046-2055.

Swart, J., \& Horton, S. (2015). From patients to teachers: The perspectives of trainers with aphasia in a UK 
Conversation Partner Scheme. Aphasiology, 29(2), 195-213.

Szalai, M., Szirmai, A., Füge, K., Makai, A., Erdélyi, G., Prémusz, V., \& Bódis, J. (2017). Special aspects of social support: Qualitative analysis of oncologic rehabilitation through a belly dancing peer support group. European Journal of Cancer Care, 26(6).

UN. (2006). Convention on the rights of persons with disabilities. New York: United Nations.

Van De Velde, D., Bracke, P., Van Hove, G., Josephsson, S., Devisch, I., \& Vanderstraeten, G. (2012). The illusion and the paradox of being autonomous, experiences from persons with spinal cord injury in their transition period from hospital to home. Disability \& Rehabilitation, 34(6), 491-502.

World Health Organisation. (2001). International classification of functioning, disability and health. Geneva: WHO.

World Health Organisation, \& World Bank. (2011). World report on disability. Geneva: WHO.

World Health Organization, \& ISCOS. (2014). International perspectives on spinal cord injury. Geneva: WHO.

\section{About the Authors}

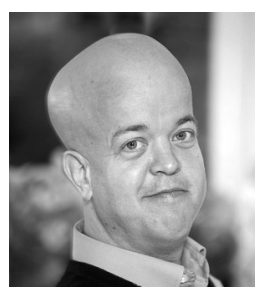

Tom Shakespeare is Professor of Disability Research at the University of East Anglia. He was formerly in the Disability and Rehabilitation team at WHO for 5 years, where he helped produce the World Report on Disability (2011) and International Perspectives on Spinal Cord Injury (2014). His publications include Disability Rights and Wrongs (2006). He is trustee of Equal Lives, the disabled people's organisation for Norfolk.

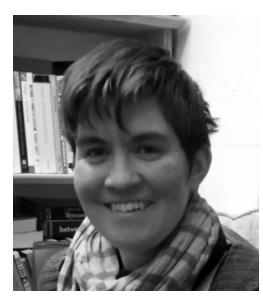

Harriet Cooper is working on a qualitative social research project entitled 'Rights-based Rehabilitation' at the University of East Anglia. She holds a PhD in Disability Studies/Medical Humanities from Birkbeck, University of London. Her work has appeared in a range of publications, including most recently in The Palgrave Handbook of Disabled Children's Childhood Studies (2018).

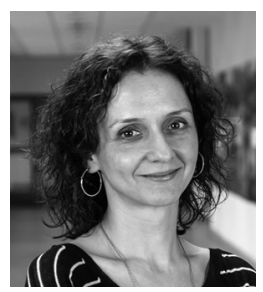

Dikmen Bezmez is Assistant Professor of Sociology at Koç University, Istanbul. Her recent research focuses on social experiences of physical rehabilitation. Some of her publications include an article on discourses surrounding the concept of "walking" in in-patient rehabilitation in Turkey, in Disability \& Society (2016), and another one on the use of medical technology in rehabilitation in the Scandinavian Journal of Disability Research (2016). She co-edited a reader in disability studies in Turkish (2011).

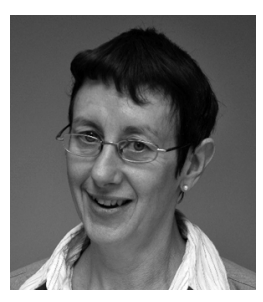

Fiona Poland is Professor of Social Research Methodology at the University of East Anglia. She co-leads a Public and Patient Involvement Research theme for the NIHR Collaboration for Leadership in Applied Health Research and Care in the East of England. Her research addresses community wellbeing and promotes cross-sector collaborations. She is Editor-in-Chief of Quality in Ageing and Older Adults. She is trustee of the Association for Research in the Voluntary and Community Sector. 